\title{
Even frequent and expected words are not identified without spatial attention
}

\author{
Mei-Ching Lien \\ Oregon State University, Corvallis, Oregon \\ ERIC RUTHRUFF \\ University of New Mexico, Albuquerque, New Mexico \\ ScotT KouchI \\ Oregon State University, Corvallis, Oregon \\ AND \\ JOEL LACHTER \\ NASA Ames Research Center, Moffett Field, California
}

\begin{abstract}
Previous studies have disagreed about the extent to which people extract meaning from words presented outside the focus of spatial attention. The present study examined a possible explanation for such discrepancies inspired by attenuation theory: Unattended words can be read more automatically when they are expected within a given context (e.g., due to frequent repetition). We presented a brief prime word in lowercase, followed by a target word in uppercase. Participants indicated whether the target word belonged to a particular category (e.g., "sports"). When we used a visual cue to draw attention to the location of the prime word, it produced substantial priming effects on target responses (i.e., especially fast responses when the prime and target words were identical or from the same category). When prime words were not attended, however, they produced no priming effects. This finding replicated even when there were only four words, each repeated 160 times during the experiment. It appears that very little word processing is possible without spatial attention, even for words that are expected and frequently presented.
\end{abstract}

Can visual objects be identified without spatial attention? For example, could a driver attending to another car interpret a passing road sign? This question has generated a large literature, in large part because it is central to how we characterize human visual attention (e.g., whether visual information processing is serial or parallel). The present study examined how spatial attention affects the semantic activation of words. In particular, we examined whether increasing the expectation for specific words within a given context, by repeating a small set of target words, would enable word processing in the absence of spatial attention. The computations involved in word recognition could potentially become much simpler when the set of possible words is greatly reduced, so it is plausible that word recognition would become more automatic and not require spatial attention.

\section{Spatial Attention in Word Processing}

The role of spatial attention in word processing has long been a contentious issue (see Neely \& Kahan, 2001, for a review). Most studies have used some variant of a priming paradigm. In a typical paradigm, a word (which we will refer to as the prime) that requires no response is presented simultaneously with, or immediately preceding, a target word to which a speeded response is made. In such studies it is well documented that, when the prime is attended, participants respond faster to related targets than to unrelated targets. In the lexical decision task (word vs. nonword), for instance, participants are faster to indicate that the target is a word (e.g., butter) when an attended prime is a related word (e.g., bread) rather than an unrelated word (e.g., nurse; e.g., Meyer \& Schvaneveldt, 1971; see Neely, 1991, for a review of associative priming effects). Similarly, people are slower to name the color of a bar if the name of a different color is printed nearby (the Stroop effect; e.g., Stroop, 1935; see MacLeod, 1991, for a review).

In most of the studies described above, the prime was presented in an attended location, even though the prime itself did not require a response. Priming effects have proven to be less consistent when attention is not directed to the prime. Some studies have suggested that spatial attention plays little or no role in semantic activation during word processing (e.g., Brown, Gore, \& Carr,

M.-C. Lien, mei.lien@oregonstate.edu 
2002; Fuentes, Carmona, Agis, \& Catena, 1994; Fuentes \& Tudela, 1992; Heil, Rolke, \& Pecchinenda, 2004; LaBerge \& Samuels, 1974; Siéroff \& Posner, 1988), whereas others have indicated an important role of spatial attention (e.g., Besner, Stolz, \& Boutilier, 1997; Chiappe, Smith, \& Besner, 1996; Dark, Johnston, Myles-Worsley, \& Farah, 1985; Stolz \& Besner, 1999; Stolz \& McCann, 2000; Stolz \& Neely, 1995; Stolz \& Stevanovski, 2004).

In an attempt to resolve the controversy, Lachter, Forster, and Ruthruff (2004) recently noted that some demonstrations of semantic activation outside spatial attention might actually be due to slippage of attention to the supposedly unattended words; that is, the so-called "unattended condition" might actually involve spatial attention to the primes on some or most trials. After taking several steps to reduce or eliminate unwanted attentional slippage to "unattended" distractor words, they eliminated priming effects in a lexical decision paradigm.

Although Lachter et al. (2004) might be correct in warning about the possibility of attentional slippage, slippage might not explain all cases of semantic activation of unattended words. It has long been noted that the Stroop paradigm produces very robust interference effects (for a review, see MacLeod, 1991), even when the color word is spatially separated from the colored stimulus, reducing incentive to attend it (e.g., Brown et al., 2002; Gatti \& Egeth, 1978). Lachter, Ruthruff, Lien, and McCann (2008) recently demonstrated that these Stroop effects (from words presented above or below a color bar) persist even when the steps recommended by Lachter et al. (2004) to prevent attentional slippage to color words are taken. For example, they (1) presented colored targets in a fixed location, promoting endogenous attention to the target location; (2) flashed colored stimuli in the target location to capture attention endogenously; and (3) presented the irrelevant color words so briefly $(50 \mathrm{msec})$ that they had no time to capture attention prior to being extinguished and masked. Despite these steps, they found significant Stroop effects (about $14 \mathrm{msec}$ in Experiment 1 and $13 \mathrm{msec}$ in Experiment 2). They even found small but reliable Stroop effects ( $4 \mathrm{msec})$ when the words were not color words but merely associated semantically with particular colors (e.g., crimson for red, and pea for green). They concluded that, although spatial attention certainly facilitates semantic activation and increases Stroop effects, it is not absolutely essential for word reading in the Stroop color-naming paradigm.

\section{Automaticity Enabled by Word Repetition}

The observation that automatic semantic activation seems to be possible in the Stroop color-naming paradigm (Lachter et al., 2008), but not in the lexical decision paradigm (Lachter et al., 2004), suggests an interesting hypothesis regarding attention. Note that Stroop experiments typically present each of four color words numerous times during a session, whereas lexical decision experiments typically present each word only once. There are many ways in which repeating words and narrowing the target set could enable more automatic word recognition.

Note that the computations involved in identifying one of four words are much simpler than those required to identify one drawn randomly from the dictionary. This is part of the reason that voice recognition programs are much more accurate when the set of possible words can be narrowed down based on context; in other words, recognition might be strongly biased toward one of the expected words. In terms of semantic network models, one could argue that the activation of expected words is elevated, allowing them to reach the threshold for identification with much less evidence than other (nonexpected) words. It is even possible that a small set of target words would be contained entirely within short-term memory. People might "identify" the words simply by noting a match with an item in short-term memory. For all of these reasons, it is highly plausible that expected/frequent words can be processed without spatial attention. This hypothesis could also be extended to explain the well-known "cocktail party effect" from the dichotic listening paradigm, in which people often notice their own names - an example of a frequently repeated and important stimulus - in an unattended channel (Moray, 1959).

This hypothesis resembles Treisman's (1960) attenuation theory, which proposes that the processing of unattended stimuli is merely attenuated rather than being filtered out entirely. Words that are familiar (such as one's own name) or highly probable within a particular context might be able to reach the threshold for conscious recognition despite some attenuation (see also Forster \& Davis, 1984). It is not clear that this simple mechanism can explain the results from more recent priming studies, however. The traditional attenuation theory asserts that unattended stimuli still receive some semantic processing, even when they fail to reach conscious awareness, and hence should produce substantial priming effects. As noted above, this is clearly not the case in the lexical decision paradigm (e.g., Lachter et al., 2004), where unattended primes often produce no priming effects.

The theory proposed in the present study therefore departs from the traditional version of the attenuation theory. Instead of proposing a reduced threshold for reaching consciousness, we propose that repeating words increases the rate at which semantic activation accumulates. Specifically, we propose that it enables activation to accumulate even for completely unattended stimuli.

There is already evidence that, for attended words, expectation does enhance stimulus processing. Ballard (1991) noted that, whereas it is computationally difficult to simultaneously identify multiple objects, it is much easier to identify a particular object in the world, or find one matching a particular internal representation. A number of neurophysiological studies suggest a mechanism that might implement the ability to find expected objects (e.g., Fuster, 1990; Fuster \& Jervey, 1981; Haenny, Maunsell, \& Schiller, 1988; Maunsell, Nealey, Sclar, \& DePriest, 1989; Miyashita \& Chang, 1988). In particular, in areas V4 (an area thought to be important in visual attention) and IT (an area thought to be important in object recognition) of macaque cortex these studies found cells that respond to what the monkey is looking for rather than what it is looking at. Such representations must serve to aid relatively low-level visual mechanisms in finding particular items. 
A few divided-attention experiments point in a similar direction. For example, Rossi and Paradiso (1995) had participants judge the spatial frequency and orientation of a Gabor patch. On one third of trials, participants were asked to determine whether a sinusoidal grating had appeared in the background. They were better at detecting sinusoids that matched the orientation of the Gabor patch when their primary task was to judge the orientation of the Gabor patch, and were better at detecting sinusoids that matched the spatial frequency of the Gabor patch when their primary task was to judge the spatial frequency of the Gabor patch. In other words, a feature in the background was more easily detected when it matched the feature the participant was attending to.

There is also considerable evidence that repetition of attended words speeds lexical decision. Kirsner and Speelman (1996), for example, found that words repeated from session to session produced faster response times than did those not repeated. These effects were especially large for words with low frequency of use in the English language.

In summary, it is likely that repetition and expectation facilitate the recognition of attended words, in effect making people more sensitive to likely targets. Note that the benefit of expectation does not necessarily depend on a deliberate attempt to take advantage of the predictability; it could simply result from increased baseline activation of the words, unconsciously biasing interpretation of word stimuli in favor of the expected stimuli (a sort of priming). The studies cited above do not, however, bear directly on the present hypothesis that such repetition enables the automatic recognition of unattended words.

\section{The Present Study}

The present study was designed to examine the hypothesis that semantic activation outside spatial attention is possible when sensitivity to particular words is elevated due to repeated presentation. If so, the results would help reconcile the discrepancy between different lines of experiments (lexical decision vs. Stroop). The general research question is also of practical interest, because in many realworld contexts stimuli are frequent and expected. In a text, for example, certain words occur more often than others, and/or are highly predictable within a certain context (e.g., He put the pizza in the __). Previous research has shown that sentence context facilitates the recognition of attended words (e.g., Stanovich \& West, 1981). This context-based facilitation might help readers to read more automatically, without needing to attend each word.

Instead of using a lexical decision paradigm, we used a categorization paradigm. Participants simply indicated whether each word did or did not belong to a prespecified category (following Lien, Ruthruff, Cornett, Goodin, \& Allen, 2008). One motivation for using a categorization paradigm is that it makes it easy to manipulate stimulus frequency (and expectation) by reducing the numbers of categories and the number of words per category. A further advantage of this categorization paradigm over the lexical decision paradigm is that a word was used as a target for all trials rather than only half of the trials, as in the lexi- cal decision paradigm. Thus, the categorization paradigm would have twice as many trials to analyze compared with a lexical decision paradigm.

For each participant, an uppercase target word was always presented in a fixed location (the top for half of the participants and the bottom for the other half; see Figure 1). Prior to the presentation of the target word, a lowercase prime word (to-be-ignored word) was presented in the opposite location. The critical manipulation was the semantic relationship between the prime word and the target word. There were three conditions, each equally likely to occur. In the identical condition, the prime word was the same as the target word (e.g., the word jeans for both the prime and the target). In the same category condition, the prime word was different from the target word but was from the same category (e.g., the prime word jeans and the target word shirt when the category was clothing). In the different category condition, the prime word was from a different category than the target word (e.g., the prime word jeans and the target word lime when the category was fruit). Using response time (RT) and proportion of error (PE) data, we established two overlapping measurements of semantic activation: the identity repetition effect and the category congruency effect (see Equations 1 and 2). The identity repetition effect is the most sensitive, but the category congruency effect eliminates any contribution from low-level perceptual priming.

$$
\begin{aligned}
& \text { Identity repetition effect }= \\
& \text { Different category - Identical }
\end{aligned}
$$

Category congruency effect $=$

Different category - Same category

As in Lachter et al. (2004; Lachter et al., 2008), we took three steps to minimize attentional slippage. First, the prime was presented for only $50 \mathrm{msec}$, followed by a 50-msec mask (see Figure 1). The target appeared immediately after the offset of the mask; thus, the interval between the onsets of the prime and target words was only $100 \mathrm{msec}$. Second, the target location was fixed throughout the whole experiment for each participant, encouraging the endogenous allocation of attention to this location only (and not the location of the prime). Third, to manipulate the exogenous allocation of attention to a particular location, we used a cue consisting of a rapid sequence of three nonwords (uppercase, lowercase, then uppercase). These cues were too brief to be processed deeply $(25 \mathrm{msec})$, but were sufficiently target-like to capture spatial attention (e.g., Folk, Remington, \& Johnston, 1992). On half of the trials, the cue drew attention to the target location. Thus, on these trials, both endogenous and exogenous attention worked together to keep attention away from the prime words. We therefore refer to this condition as uncued or unattended prime. On the other half of the trials, the cue drew attention to the prime location. We refer to this condition as cued or attended prime. Note that the prime word was always presented and masked within $200 \mathrm{msec}$ of cue onset, so there was no time for participants to move their eyes. Hence, any differences in priming effects between these conditions would be due to the allocation of atten- 


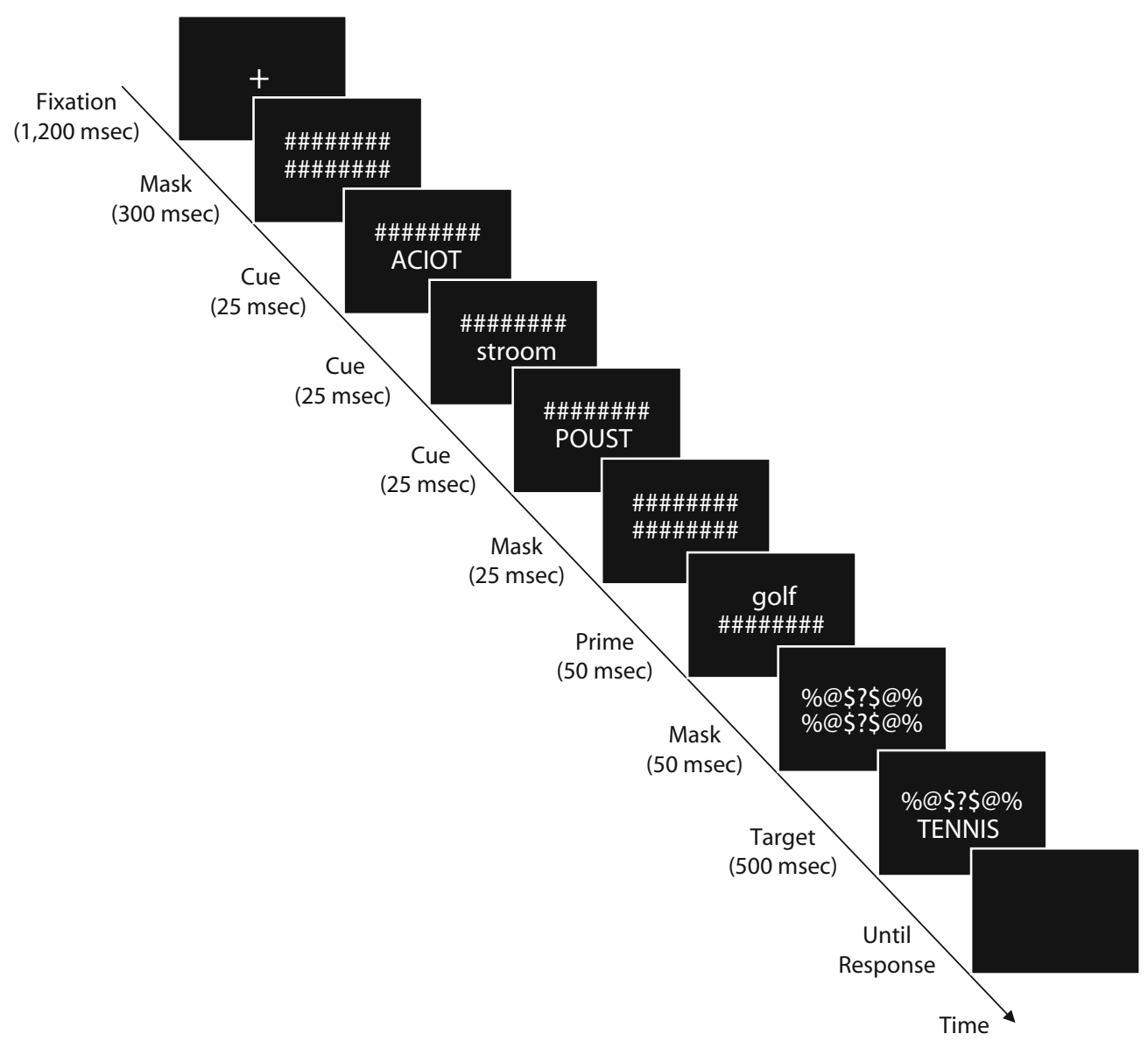

Figure 1. An example event sequence for the uncued prime condition of Experiment 1. In this example, the prime and the target words belonged to the same category (e.g., "sports"), which was named prior to each block. The target was always presented in the bottom location. Trials began with a fixation cross, followed by a mask. Three nonwords, alternating in uppercase and lowercase, appeared in the location opposite to the subsequent prime word (because the condition shown is the uncued condition). The prime word was always printed in lowercase, whereas the target word was always printed in uppercase.

tion, not to the distance from fixation (which was the same for both conditions).

We expect that attended (cued) primes will be identified, at least partially (despite being presented relatively briefly). They can then influence target processing in one of several ways. If the prime is identical to the target, identification of the prime should contribute activation to that same node in lexical memory. The prime word might also facilitate responding to the target word by activating the corresponding response; for example, if the prime word belongs to the same category as the target word, it will activate the "related" category and its response. This benefit can accrue even if the target and prime words are not identical but merely belong to the same category. By the same reasoning, there might be a cost when the prime and target words belong to different categories and therefore are associated with different responses. The end result is that attended primes are identified and therefore would produce identity repetition effects and category congruency effects. The critical question, then, is whether unattended (uncued) primes can also be identified and produce identity repetition and category congruency effects.
Experiment 1 measured the identity repetition effect and the category congruency effect using a large set of 162 target words and each word repeated only 4 times within a session. Experiments 2 and 3 then examined whether both identity repetition and category congruency effects increase when the words are presented much more frequently within a session ( 8 target words repeated 80 times in Experiment 2 and 4 target words repeated 160 times in Experiment 3). If semantic activation outside spatial attention is possible only when word representations are already highly activated (i.e., due to repeated presentation within a session), one would expect to obtain substantial identity repetition and category congruency effects that increase as the words are repeated more often within a session (i.e., increased from Experiment 1 to Experiment 3).

\section{EXPERIMENT 1}

Experiment 1 measured the identity repetition effect and the category congruency effect when each word was presented only occasionally within a session. We used 18 different category lists, taken from Lien et al. (2008). ${ }^{1}$ Each 
category contained 18 words. To make the session length manageable, however, each participant received only 9 of these categories in 9 different experimental blocks. Within each block, half of the target words were related to the category and half were unrelated. Each of the 18 words belonging to that category was presented twice within the block. These words were also presented twice as the target during other blocks, when they were unrelated (using exactly the same words for the related and unrelated conditions ensures that they are perfectly matched). Thus, overall, each word was presented four times as the target during the session for each participant.

\section{Method}

Participants. Sixty undergraduate students from Oregon State University and the University of New Mexico participated in exchange for extra course credit. Their mean age was 19; age range, 18-30. They were all native English speakers and had normal or corrected-to-normal vision.

Apparatus and Stimuli. Stimuli, presented on 19-in. monitors, were viewed from a distance of about $55 \mathrm{~cm}$. All stimuli were presented in white against a black background. Each trial started with a fixation display, which consisted of a centrally located plus sign $\left(0.83^{\circ} \times 0.83^{\circ}\right)$. As is shown in Figure 1, each of the subsequent displays contained top and bottom rows of characters, which were centered $1.25^{\circ}$ apart. The premask display consisted of two rows of hash marks ("\#\#\#\#\#\#\#\#). Each hash mark was $0.52^{\circ} \times 0.83^{\circ}$. The cue display consisted of one row of hash marks and a sequence of three nonwords printed in uppercase, lowercase, then uppercase. The prime display consisted of hash marks in one row and a word printed in lowercase in a different row. The postmask display consisted of two rows of character strings (“\%@\$?\$@\%”). The target display consisted of character strings in one row and a word printed in uppercase in a different row. Each of the uppercase letters and symbols subtended a visual angle of approximately $0.73^{\circ}$ wide $\times 0.83^{\circ}$ high, whereas each of the lowercase letters subtended a visual angle of approximately $0.52^{\circ}$ wide $\times 0.83^{\circ}$ high.

Design and Procedure. Prior to each block, we presented a category word (e.g., sports) on the screen. Participants were asked to remember the category word for that particular block. As is shown in Figure 1, each trial started with the fixation display for 1,200 msec, followed by the premask display for $300 \mathrm{msec}$. The three cue displays then appeared sequentially for $25 \mathrm{msec}$ each, followed by the premask display for $25 \mathrm{msec}$. The prime display then appeared for $50 \mathrm{msec}$, followed by the postmask display for $50 \mathrm{msec}$, and the target display for $500 \mathrm{msec}$. Thus, the interval between the onsets of the prime display and the target display was $100 \mathrm{msec}$. The participants' task was to indicate whether the uppercase target word was semantically related or unrelated to the category word presented on the screen prior to each block (e.g., the target word GOLF would be semantically related to the category word sports, but the target word PLUM would be unrelated; see Lien et al., 2008). They were to press the key "Z" with the left index finger for related target words, and the key "M" with the right index finger for unrelated target words. Auditory feedback (a $22-\mathrm{kHz}$ tone) was presented $100 \mathrm{msec}$ after incorrect responses, and silence lasted for $100 \mathrm{msec}$ after correct responses. Immediately after the feedback, the next trial began with the fixation display for $1,200 \mathrm{msec}$.

The location of the target word was fixed throughout the whole experiment (the top row for half of the participants and the bottom row for the other half). Thus, participants were encouraged to endogenously allocate spatial attention to that target location. The prime word always appeared in the opposite location as the target word. The target word was either semantically related $(50 \%$ of trials) or unrelated (50\% of trials) to the category word. Each of the three prime-target conditions occurred equally often. In the identical condition, the prime word was the same as the target word. In the same category condition, the prime word was different from the target word, but was from the same category. In the different category condition, the prime word was from a different category than the target word. As a consequence, the prime word belonged to the same category as the target on two thirds of the trials. Each word appeared four times as the target for each participant, two times in the block when its category was selected (related), and two times when other categories were selected (unrelated).

The cue appeared $50 \%$ of the time in the prime word location (cued or attended prime condition) and $50 \%$ of the time in the target word location (uncued or unattended prime condition). Participants performed one practice block of 36 trials, followed by nine experimental blocks of 72 trials each (a total of 648 experimental trials). They received a summary of their mean RT and accuracy at the end of each block. They were encouraged to take a break before beginning the next block.

\section{Results}

Trials were excluded from analysis if the RT was less than $100 \mathrm{msec}$ or greater than $2,000 \mathrm{msec}(0.28 \%$ of the trials). Error trials were also excluded from RT analyses. Table 1 shows the resulting mean RT and PE. Although we report the overall data analysis for the sake of completeness, note that our experimental logic rests specifically on the identity repetition effect (see Equation 1) and the category congruency effect (see Equation 2). The between-subjects factor was target location (top vs. bottom), whereas the within-subjects factors were prime cuing condition (cued vs. uncued), prime-target relation-

Table 1

Response Times (RTs, in Milliseconds) and Proportions of Errors (PEs) in Experiment 1 As a Function of Target Location, Prime Cuing Condition, Prime-Target Relationship, and Target Relatedness

\begin{tabular}{|c|c|c|c|c|c|c|c|c|c|c|c|c|}
\hline \multirow{4}{*}{$\begin{array}{c}\text { Prime } \\
\text { Cuing } \\
\text { Condition }\end{array}$} & \multicolumn{12}{|c|}{ Target Relatedness } \\
\hline & \multicolumn{6}{|c|}{ Related } & \multicolumn{6}{|c|}{ Unrelated } \\
\hline & \multicolumn{2}{|c|}{ Identical } & \multicolumn{2}{|c|}{$\begin{array}{c}\text { Same } \\
\text { Category }\end{array}$} & \multicolumn{2}{|c|}{$\begin{array}{l}\text { Different } \\
\text { Category }\end{array}$} & \multicolumn{2}{|c|}{ Identical } & \multicolumn{2}{|c|}{$\begin{array}{c}\text { Same } \\
\text { Category }\end{array}$} & \multicolumn{2}{|c|}{$\begin{array}{l}\text { Different } \\
\text { Category }\end{array}$} \\
\hline & RT & $\mathrm{PE}$ & RT & $\mathrm{PE}$ & RT & $\mathrm{PE}$ & RT & $\mathrm{PE}$ & RT & $\mathrm{PE}$ & RT & PE \\
\hline \multicolumn{13}{|c|}{ Target on Top } \\
\hline Cued & 572 & .084 & 585 & .093 & 594 & .096 & 608 & .064 & 616 & .067 & 634 & .087 \\
\hline Uncued & 582 & .085 & 584 & .100 & 582 & .086 & 622 & .091 & 616 & .073 & 618 & .072 \\
\hline \multicolumn{13}{|c|}{ Target on Bottom } \\
\hline Cued & 562 & .075 & 567 & .069 & 583 & .097 & 610 & .067 & 613 & .078 & 621 & .084 \\
\hline Uncued & 575 & .081 & 570 & .086 & 572 & .082 & 613 & .065 & 611 & .081 & 621 & .083 \\
\hline
\end{tabular}


ship (identical, same category, or different category), and target relatedness (related vs. unrelated). An ANOVA was performed, with the $p$ values being adjusted using the Greenhouse-Geisser epsilon correction for nonsphericity, where appropriate. An alpha level of .05 was set for determining statistical significance.

Overall data analyses. The RT analyses revealed an overall priming effect: RT was shorter when the prime and the target were identical $(593 \mathrm{msec})$ or from the same category $(595 \mathrm{msec})$ than when they were from different categories $(603 \mathrm{msec})[F(2,116)=17.79, p<.0001$, $\left.\eta_{\mathrm{p}}^{2}=.23\right]$. Importantly, however, this effect interacted with prime cuing condition $\left[F(2,116)=19.84, p<.0001, \eta_{\mathrm{p}}^{2}=\right.$ $.25]$. We will defer detailed discussion of this interaction until the Identity Repetition Effects and Category Congruency Effects sections, below. The data analyses also revealed that RT was $40 \mathrm{msec}$ shorter when the target was related to the category word $(577 \mathrm{msec})$ than when it was unrelated $(617 \mathrm{msec})\left[F(1,58)=93.97, p<.0001, \eta_{\mathrm{p}}^{2}=\right.$ .62]. No other effects were significant. In particular, there was no main effect of either target location or prime cuing condition.

Similar results were obtained in the PE data. Mean PE was smaller when the prime word and the target word were identical (.077) or from the same category (.081) than when they were from different categories (.086) $\left[F(2,116)=3.18, p<.05, \eta_{\mathrm{p}}^{2}=.05\right]$. As in the RT data, this effect was modulated by prime cuing condition $\left[F(2,116)=5.42, p<.01, \eta_{\mathrm{p}}^{2}=.09\right]$ (see detailed discussion in the Identity Repetition Effects and Category Congruency Effects sections, below). The threeway interaction between target location, target relatedness, and prime-target relationship was also significant $\left[F(2,116)=3.27, p<.05, \eta_{\mathrm{p}}^{2}=.002\right]$. When the target word was on the top location, the PE was relatively small when the target was an unrelated word for all three prime-target conditions. When the target word was on the bottom location, the PE was smaller for unrelated target words only for the identical and different category conditions (see Table 1).

Identity repetition effects. To assess the identity repetition effect, we included only the data from the identical condition and different category condition. The ANOVA was performed on RT and PE with the factors prime cuing condition (cued vs. uncued) and prime-target relationship (identical vs. different category). The overall identity repetition effect on RT was $10 \mathrm{msec}[F(1,58)=33.83$, $\left.p<.0001, \eta_{\mathrm{p}}^{2}=.37\right]$. Most importantly, the interaction between prime cuing condition and prime-target relationship was significant $\left[F(1,58)=30.77, p<.0001, \eta_{\mathrm{p}}^{2}=\right.$ .91]; an identity repetition effect was obtained for cued primes (with a $95 \%$ confidence interval of $20 \pm 6 \mathrm{msec}$ ) but not for uncued primes $(0 \pm 4 \mathrm{msec}$; see Figure $2 \mathrm{~A})$. Simple main effects analyses confirmed that the identity repetition effect was significant for the cued prime condition $\left[F(1,58)=48.08, p<.0001, \eta_{\mathrm{p}}^{2}=.45\right]$, but not for the uncued prime condition $(F<1)$.

The PE data show a similar pattern to the RT data. The overall identity repetition effect on PE was .009 $\left[F(1,58)=6.43, p<.05, \eta_{\mathrm{p}}^{2}=.10\right]$; the PE was smaller when the prime and the target words were identical (.076) than when they were from different categories (.086). As in the RT data, the identity repetition effect was obtained for the cued prime condition (.018 \pm .011 , using a $95 \%$ confidence interval) but not for the uncued prime condition $(0 \pm .008)\left[F(1,58)=8.25, p<.01, \eta_{\mathrm{p}}^{2}=.13\right]$. Simple main effects analyses again confirmed that the identity repetition effect was significant for cued primes $\left[F(1,58)=10.97, p<.01, \eta_{\mathrm{p}}^{2}=.16\right]$, but not for uncued primes $(F<1)$.

Category congruency effects. In addition to the identity repetition effect, we also examined the category congruency effect. We included data from the same and different category conditions only. The ANOVA was performed on RT and PE with the factors of prime cuing condition (cued vs. uncued) and prime-target relationship (same category vs. different category). The overall category congruency effect on RT was $8 \mathrm{msec}[F(1,58)=17.96$, $\left.p<.0001, \eta_{\mathrm{p}}^{2}=.24\right]$; RT was shorter when the prime and the target were from the same category $(595 \mathrm{msec})$ than when they were from different categories $(603 \mathrm{msec})$. RT for the target word was faster when the prime was uncued $(597 \mathrm{msec})$ than when it was cued $(602 \mathrm{msec})[F(1,58)=$ $\left.10.30, p<.01, \eta_{\mathrm{p}}^{2}=.15\right]$. Most importantly, a substantial category congruency effect was obtained for the cued prime condition (13 $\pm 5 \mathrm{msec}$, using a $95 \%$ confidence interval) but not for the uncued prime condition $(3 \pm 4 \mathrm{msec})\left[F(1,58)=10.30, p<.01, \eta_{\mathrm{p}}^{2}=.15\right]$; see Figure 2B. Simple main effects analyses confirmed that the category congruency effect was significant for cued primes $\left[F(1,58)=24.83, p<.0001, \eta_{\mathrm{p}}^{2}=.30\right]$, but not for uncued primes $\left[F(1,58)=1.18, p=.2829, \eta_{\mathrm{p}}^{2}=.02\right]$.

In the PE data, the category congruency effect was obtained for the cued prime condition (with a $95 \%$ confidence interval of .014 \pm .011$)$ but not for the uncued prime condition $(-.004 \pm .009)[F(1,58)=7.41, p<$ $\left..01, \eta_{\mathrm{p}}^{2}=.11\right]$. Simple main effects analyses confirmed that the category congruency effect was significant for cued primes $\left[F(1,58)=6.23, p<.05, \eta_{\mathrm{p}}^{2}=.10\right]$, but not for uncued primes $(F<1)$. No other effects were found to be significant.

\section{Discussion}

Experiment 1 evaluated whether unattended words could be processed sufficiently to produce identity repetition and category congruency effects when each word was presented only occasionally. We used a large set of 162 words, each presented as a target only four times during an experimental session. As had Lachter et al. (2004; Lachter et al., 2008), we took several steps to minimize attentional slippage to the prime words and thus control the allocation of the spatial attention (short presentation, mask, and a cue). After taking these precautions, we found both identity repetition effect and category congruency effect only when the prime word was attended (i.e., cued), not when it was unattended (i.e., uncued). These findings suggest that the visual words received little semantic activation in the absence of the spatial attention. They also indicate that Lachter et al.'s (2004) findings from the lexical decision paradigm generalize to the categorization paradigm. 

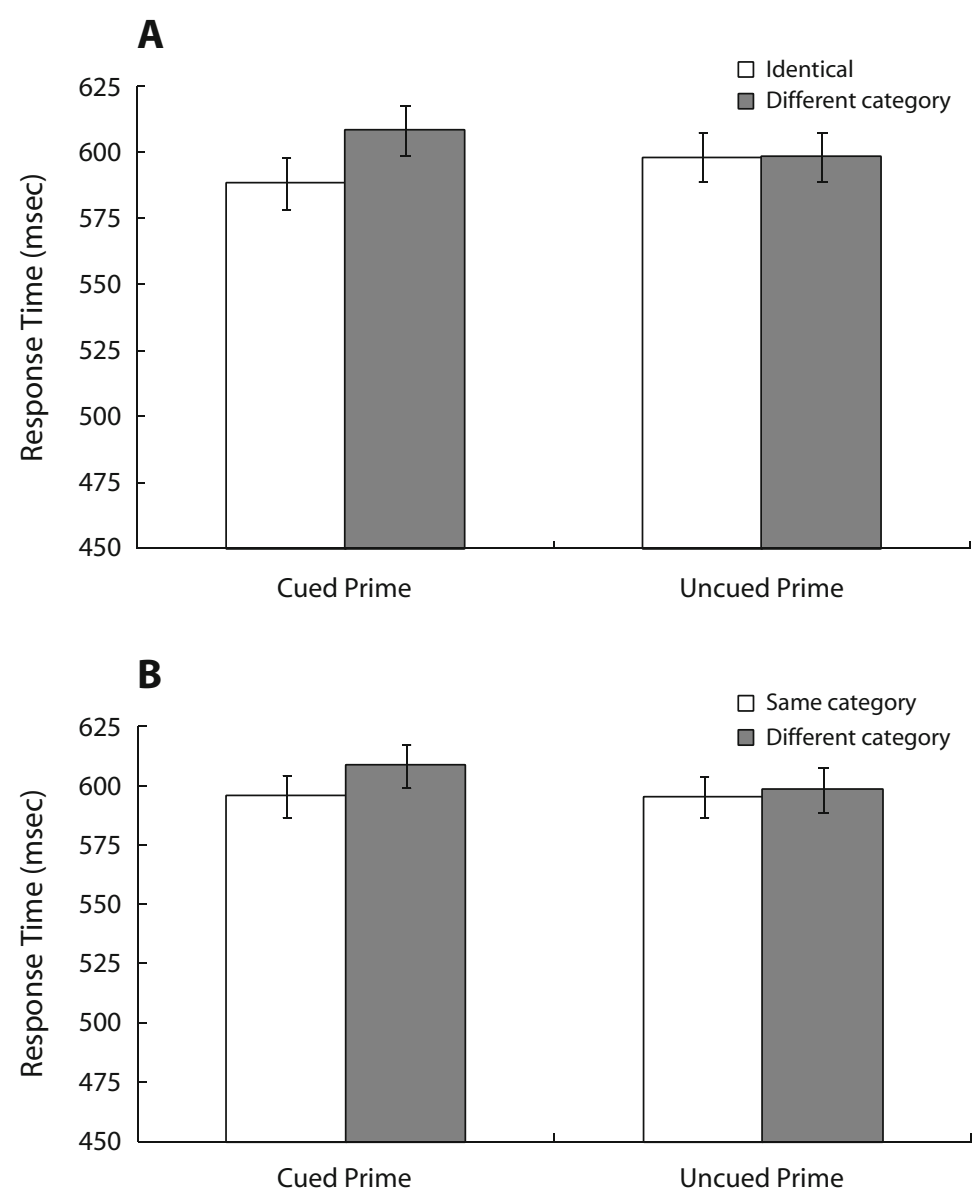

Figure 2. Mean response times (RTs) for cued and uncued primes in Experiment 1 as a function of prime-target relationship (identical, same category, or different category). (A) Mean RTs for the identical condition and the different category condition (the difference between these conditions is the identity repetition effect). (B) Mean RTs in the same category condition (excluding the identical trials) and the different category condition (the difference between these conditions is the category congruency effect). Error bars represent the standard errors of the means.

Because the prime word belonged to the same category (both identical and same category conditions) as the target on two thirds of the trials, there might appear to have been an incentive for participants to use the primes (if possible). Accordingly, participants might have endogenously attended to both the top and bottom locations, waiting to take advantage of the prime. This view would predict both identity repetition effect and category congruency effect, even when the prime was uncued. Our findings were clearly inconsistent with this prediction. The reason might be that our primes were presented so briefly $(50 \mathrm{msec})$ that participants were typically not aware of them. Even if they were aware, the benefit might be trivial compared with the costs of deliberate using the prime and thus attending to the wrong location when the target appeared.

\section{EXPERIMENT 2}

Experiment 1 yielded no evidence that semantic activation of unattended words occurs. Nevertheless, as noted above, spatial attention might be less necessary for words that are expected within a given context and/or have been frequently presented. To address this issue, Experiment 2 reduced the set of words from 162 to only 8 . Each word was now presented 80 times per participant (as opposed to 4 times per participant in Experiment 1). As in Experiment 1, our main interest was whether the prime word could produce identity repetition effects and category congruency effects in the absence of the spatial attention.

\section{Method}

Participants. There were 72 new participants, drawn from the same participant pool as in Experiment 1. Their mean age was 19; age range, 18-38. They were all native English speakers and had normal or corrected-to-normal vision.

Apparatus, Stimuli, and Procedure. The tasks, stimuli, and equipment were the same as in Experiment 1, except that each participant received only one category containing four related words and four unrelated words drawn from other categories throughout the whole experimental session. We used the same categories as in 
Table 2

Response Times (RTs, in Milliseconds) and Proportions of Errors (PEs) in Experiment 2 As a Function of Target Location, Prime Cuing Condition, Prime-Target Relationship, and Target Relatedness

\begin{tabular}{|c|c|c|c|c|c|c|c|c|c|c|c|c|}
\hline \multirow{4}{*}{$\begin{array}{c}\text { Prime } \\
\text { Cuing } \\
\text { Condition } \\
\end{array}$} & \multicolumn{12}{|c|}{ Target Relatedness } \\
\hline & \multicolumn{6}{|c|}{ Related } & \multicolumn{6}{|c|}{ Unrelated } \\
\hline & \multicolumn{2}{|c|}{ Identical } & \multicolumn{2}{|c|}{$\begin{array}{c}\text { Same } \\
\text { Category }\end{array}$} & \multicolumn{2}{|c|}{$\begin{array}{l}\text { Different } \\
\text { Category }\end{array}$} & \multicolumn{2}{|c|}{ Identical } & \multicolumn{2}{|c|}{$\begin{array}{c}\text { Same } \\
\text { Category }\end{array}$} & \multicolumn{2}{|c|}{$\begin{array}{l}\text { Different } \\
\text { Category }\end{array}$} \\
\hline & RT & $\mathrm{PE}$ & RT & $\mathrm{PE}$ & RT & $\mathrm{PE}$ & RT & $\mathrm{PE}$ & RT & $\mathrm{PE}$ & RT & $\mathrm{PE}$ \\
\hline \multicolumn{13}{|c|}{ Target on Top } \\
\hline Cued & 533 & .055 & 539 & .056 & 558 & .097 & 548 & .068 & 554 & .053 & 578 & .092 \\
\hline Uncued & 543 & .060 & 543 & .067 & 549 & .072 & 556 & .064 & 562 & .065 & 561 & .066 \\
\hline \multicolumn{13}{|c|}{ Target on Bottom } \\
\hline Cued & 522 & .053 & 530 & .068 & 546 & .106 & 535 & .077 & 541 & .055 & 559 & .091 \\
\hline Uncued & 541 & .076 & 540 & .072 & 538 & .070 & 538 & .065 & 542 & .061 & 542 & .065 \\
\hline
\end{tabular}

Experiment 1; each category was used equally often across participants. In addition, each participant received 10 blocks of 64 trials each ( 1 practice block and 9 experimental blocks).

\section{Results}

The data analysis was similar to that in Experiment 1. Application of the RT cutoffs eliminated approximately $2.07 \%$ of trials. Table 2 shows the mean RT and PE.

Overall data analyses. The patterns obtained from overall data analyses were similar to those reported in Experiment 1 . The RT analyses revealed that RT was shorter when the prime and the target were identical $(539 \mathrm{msec})$ and when they were from the same category $(544 \mathrm{msec})$ than when they were from different categories (554 msec) $\left[F(2,140)=35.86, p<.0001, \eta_{\mathrm{p}}^{2}=.34\right]$. Most importantly, the interaction between prime cuing condition and prime-target relationship was again significant $\left[F(2,140)=38.77, p<.0001, \eta_{\mathrm{p}}^{2}=.36\right]$; see the Discussion section below. RT was $11 \mathrm{msec}$ shorter when the target was related to the category $(540 \mathrm{msec})$ than when it was unrelated $(551 \mathrm{msec})[F(1,70)=22.47, p<.0001$, $\left.\eta_{\mathrm{p}}^{2}=.24\right]$. This effect also interacted with prime cuing condition. Mean RT was $4 \mathrm{msec}$ shorter for cued primes than for uncued primes when the target word was related to the category but was $3 \mathrm{msec}$ slower when the target word was unrelated $\left[F(1,70)=7.39, p<.01, \eta_{\mathrm{p}}^{2}=.10\right]$.

The PE analyses revealed that PE was smaller when the prime and the target words were identical (.065) or from the same category (.062) than when they were from different categories $(.068)[F(2,140)=16.67, p<.0001$, $\left.\eta_{\mathrm{p}}^{2}=.19\right]$. The PE was smaller for uncued primes (.067) than for cued primes $(.073)[F(1,70)=4.40, p<.05$, $\left.\eta_{\mathrm{p}}^{2}=.06\right]$. As with the RT data, the interaction between prime cuing condition and prime-target relationship was significant on $\operatorname{PE}\left[F(2,140)=10.89, p<.001, \eta_{\mathrm{p}}^{2}=.13\right]$; see the Discussion section below. The PE was higher for the unrelated than for the related target words in the identical condition (.068 vs. .061, respectively) but was lower in the same category condition (.059 vs. .066, respectively) and in the different category condition (.079 vs. .086, respectively) $\left[F(2,140)=4.55, p<.05, \eta_{\mathrm{p}}^{2}=.06\right]$. The three-way interaction between these variables and prime cuing condition was also significant $[F(2,140)=3.52$, $\left.p<.05, \eta_{\mathrm{p}}^{2}=.05\right]$; a higher PE for the unrelated target word than for the related target word was obtained only for cued primes in the identical condition (see Table 2).

Identity repetition effects. The overall identity repetition effect on RT was $15 \mathrm{msec}[F(1,72)=50.49, p<$ $\left..0001, \eta_{\mathrm{p}}^{2}=.42\right]$; mean RT was shorter when the prime and target were identical $(539 \mathrm{msec})$ than when they were from different categories (554 msec). Most importantly, the identity repetition effect was obtained when the prime was cued (with a $95 \%$ confidence interval of $26 \pm 6 \mathrm{msec}$ ) but not when it was uncued $(3 \pm 4 \mathrm{msec})[F(1,70)=56.09$, $\left.p<.0001, \eta_{\mathrm{p}}^{2}=.44\right]$; see Figure $3 \mathrm{~A}$. Simple main effects analyses confirmed that the identity repetition effect was significant for cued primes $[F(1,70)=75.58, p<.0001$, $\left.\eta_{\mathrm{p}}^{2}=.52\right]$ but not for uncued primes $[F(1,70)=2.41, p=$ $\left..1248, \eta_{\mathrm{p}}^{2}=.03\right]$.

The PE data were similar to the RT data. The overall identity repetition effect on PE was $.020[F(1,70)=$ $\left.17.81, p<.0001, \eta_{\mathrm{p}}^{2}=.20\right]$; the PE was smaller when the prime and target were identical (.065) than when they were from different categories (.083). The PE for the target word was .013 smaller when the prime was uncued $(.067)$ than when it was cued $(.080)[F(1,70)=16.39$, $\left.p<.0001, \eta_{\mathrm{p}}^{2}=.19\right]$. As in the RT data, the identity repetition effect was obtained when the prime was cued (.033 \pm .014 , using the $95 \%$ confidence interval) but not when it was uncued $(.002 \pm .009)[F(1,70)=13.64, p<$ $\left..001, \eta_{\mathrm{p}}^{2}=.16\right]$. Simple main effects analyses confirmed that the identity repetition effect was significant for cued primes $\left[F(1,70)=21.29, p<.0001, \eta_{\mathrm{p}}^{2}=.23\right]$ but not for uncued primes $(F<1)$.

Category congruency effects. As in Experiment 1, we also examined the category congruency effect including only the data from the same and different category conditions. The overall category congruency effect on RT was $10 \mathrm{msec}\left[F(1,70)=30.25, p<.0001, \eta_{\mathrm{p}}^{2}=.30\right]$; the RT was shorter when the prime and target were from the same category $(544 \mathrm{msec})$ than when they were from different categories $(554 \mathrm{msec})$. RT for the target word was shorter when the prime was uncued $(547 \mathrm{msec})$ than when it was cued $(551 \mathrm{msec})\left[F(1,70)=7.39, p<.01, \eta_{\mathrm{p}}^{2}=.10\right]$, suggesting that the attended prime word slowed down the processing of the target word. Most importantly, a category congruency effect was obtained when the prime word was cued (with a $95 \%$ confidence interval of $19 \pm 5 \mathrm{msec}$ ) but 

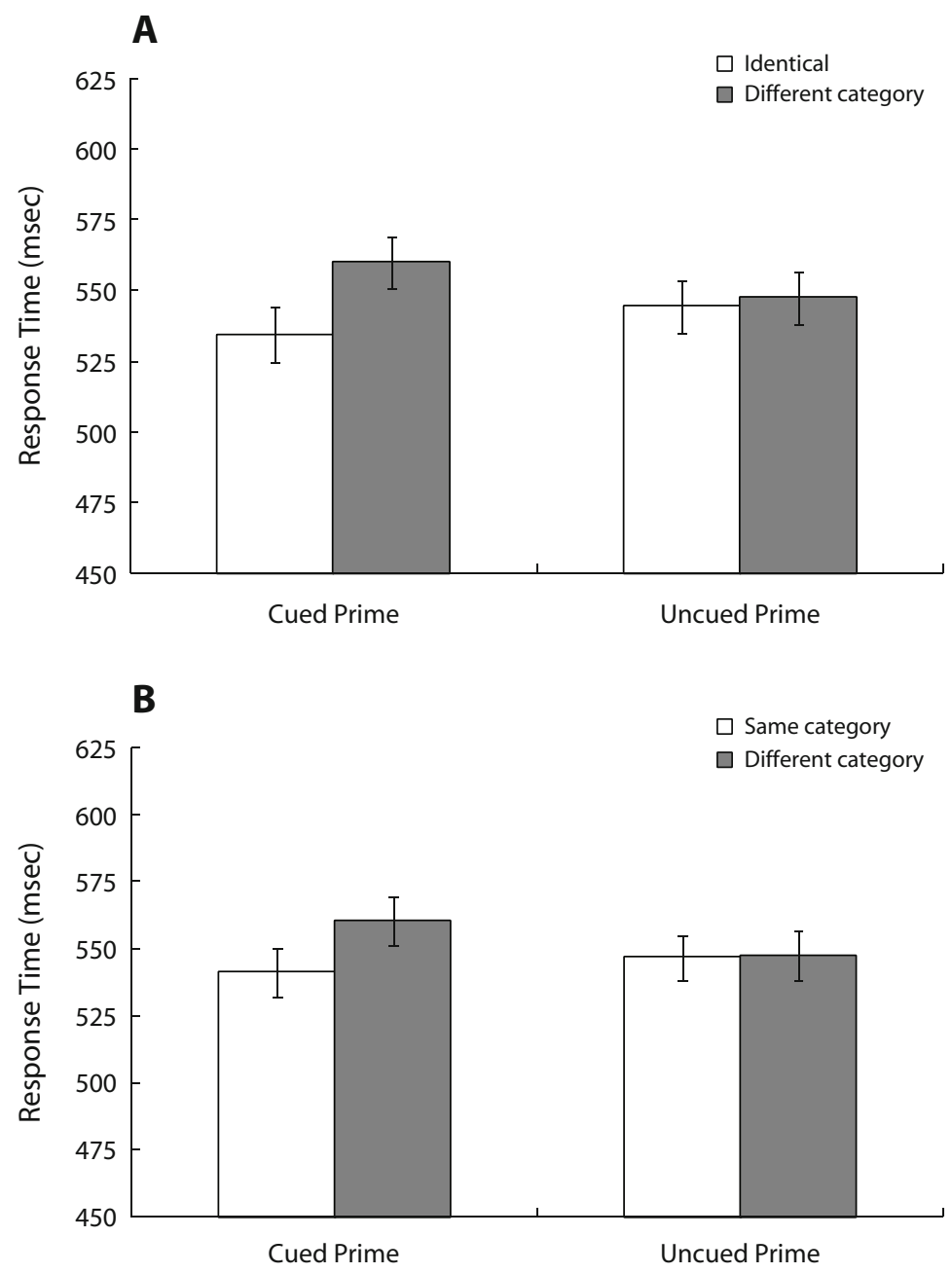

Figure 3. Mean response times (RTs) for cued and uncued primes in Experiment 2 as a function of prime-target relationship (identical, same category, or different category). (A) Mean RTs for the identical condition and the different category condition (the difference between these conditions is the identity repetition effect). (B) Mean RTs in the same category condition (excluding the identical trials) and the different category condition (the difference between these conditions is the category congruency effect). Error bars represent the standard errors of the means.

not when it was uncued $(1 \pm 4 \mathrm{msec})[F(1,70)=42.17$, $\left.p<.0001, \eta_{\mathrm{p}}^{2}=.38\right]$; see Figure 3B. Simple main effects analyses revealed that the category congruency effect was significant for cued primes $[F(1,70)=65.01, p<.0001$, $\left.\eta_{\mathrm{p}}^{2}=.48\right]$, but not for uncued primes $(F<1)$.

The PE data analyses revealed a similar pattern as in the RT data. The overall category congruency effect on PE was $.020\left[F(1,70)=21.60, p<.0001, \eta_{\mathrm{p}}^{2}=.24\right]$; the $\mathrm{PE}$ was smaller when the prime and target were from the same category (.062) than when they were from different categories (.083). PE for the target word was smaller when the prime was uncued $(.067)$ than when it was cued $(.077)\left[F(1,70)=8.67, p<.01, \eta_{\mathrm{p}}^{2}=.11\right]$. Most importantly, the category congruency effect was obtained when the prime was cued (with a $95 \%$ confidence interval of $.039 \pm .016)$ but not when it was uncued $(.002 \pm .010)$ $\left[F(1,70)=13.13, p<.001, \eta_{\mathrm{p}}^{2}=.16\right]$. Simple main ef- fects analyses confirmed that the category congruency effect was significant for cued primes $[F(1,70)=23.96$, $\left.p<.0001, \eta_{\mathrm{p}}^{2}=.25\right]$, but not for uncued primes $(F<1)$.

\section{Discussion}

The purpose of Experiment 2 was to examine whether semantic activation outside spatial attention is possible when the set of target words is small, increasing the level of expectation for those target words. Thus, we increased the activation of word nodes by repeatedly presenting the same small set of words throughout the whole experiment. Each participant received only one of the categories used in Experiment 1, and it consisted of only 4 related words and 4 unrelated words (compared with 9 categories of 162 related and 162 unrelated words in Experiment 1). Instead of repeating each word only 4 times per participant, as in Experiment 1, each word was now presented 80 times. 
This change decreased overall RT from 597 msec in Experiment 1 to $546 \mathrm{msec}$ in Experiment 2.

Despite the high frequency of presentation of the words, the identity repetition effect and the category congruency effect were nearly identical to those of Experiment 1. Both effects on RT and PE were still evident only when the prime was cued (attended), not when it was uncued (unattended). These findings suggest that spatial attention is needed for semantic activation even for words that are highly activated.

\section{EXPERIMENT 3}

Experiment 3 took a further step to increase the frequency of the words by including only four words for each category (two related and two unrelated). This modification brings us closer to Stroop studies, which typically use four color words within an experimental session (e.g., Lachter et al., 2008). Each word was now presented 160 times as the target word per participant, twice as often as in Experiment 2.

\section{Method}

Participants. There were 78 new participants, drawn from the same participant pool as in previous experiments. Their mean age was 20; age range, 18-35. They were all native English speakers and had normal or corrected-to-normal vision.

Apparatus, Stimuli, and Procedure. The tasks, stimuli, and equipment were the same as in Experiment 2, except that each participant received only one category containing two related words and two unrelated words drawn from other categories. Each word was repeated 160 times throughout the whole experiment. Each participant received 10 blocks of 64 trials each (1 practice block and 9 experimental blocks).

\section{Results}

The data analysis was similar to that in Experiment 2. Application of the RT cutoffs eliminated $0.51 \%$ of trials. Table 3 shows the resulting mean RT and PE.

Overall data analyses. The patterns obtained from the overall data analysis were similar to those reported in Experiment 2. RT was $11 \mathrm{msec}$ shorter when the target was related to the category $(490 \mathrm{msec})$ than when it was unrelated $(498 \mathrm{msec})\left[F(1,76)=16.00, p<.0001, \eta_{\mathrm{p}}^{2}=\right.$ .17]. Unlike the previous experiments, the difference in
RT between related and unrelated targets was significantly larger when the target appeared in the bottom location (difference $=13 \mathrm{msec}$ ) than when it appeared in the top location (difference $=2 \mathrm{msec}$ ) $[F(1,76)=8.24, p<.01$, $\left.\eta_{\mathrm{p}}^{2}=.10\right]$.

Again, mean RT varied significantly across the identical (489 msec), same category (493 msec), and different category $(501 \mathrm{msec})$ condition $[F(2,152)=41.68, p<$ $\left..0001, \eta_{\mathrm{p}}^{2}=.35\right]$. However, as in Experiments 1 and 2, the interaction between prime cuing condition and primetarget relationship was significant $[F(2,152)=31.05, p<$ $.0001, \eta_{\mathrm{p}}^{2}=.29$ ] (see discussion in the Identity Repetition Effects and Category Congruency Effects sections, below). Furthermore, mean RT was $4 \mathrm{msec}$ faster for cued primes than for uncued primes when the target word was related to the category but was $1 \mathrm{msec}$ slower when the target word was unrelated $[F(1,76)=12.82, p<.001$, $\left.\eta_{\mathrm{p}}^{2}=.14\right]$.

The PE analyses revealed that PE was higher when the prime and target were from different categories (.071) than when they were from the same category $(.052)$ or identical $(.050)\left[F(2,152)=25.87, p<.0001, \eta_{\mathrm{p}}^{2}=.25\right]$. The PE was higher for the related target word (.062) than for the unrelated target word $(.054)[F(1,76)=5.83, p<$ $\left..05, \eta_{\mathrm{p}}^{2}=.07\right]$. As with the RT data analyses, the interaction between prime cuing condition and prime-target relationship was significant $[F(2,152)=18.70, p<.001$, $\left.\eta_{\mathrm{p}}^{2}=.20\right]$; see below.

The difference in PE between the unrelated and related target words was larger in the different category condition (.078 vs. .063, respectively) than in the same category condition (.054 vs. .051, respectively) and the identical condition (.053 vs. .047, respectively) $[F(2,152)=3.25$, $\left.p<.05, \eta_{\mathrm{p}}^{2}=.04\right]$. The four-way interaction between target location (top vs. bottom), prime cuing condition (cued vs. uncued), prime-target relationship (identical, same category, or different category), and target relatedness (related vs. unrelated) was significant $[F(2,152)=$ $\left.3.88, p<.05, \eta_{\mathrm{p}}^{2}=.05\right]$. For both related and unrelated target words, the PE was smaller for cued primes than for uncued primes in the identical condition but was larger in the different category condition. However, the results were mixed in the same category condition, depending on the target location (see Table 3).

Table 3

Response Times (RTs, in Milliseconds) and Proportions of Errors (PEs) in Experiment 3 As a Function of Target Location, Prime Cuing Condition, Prime-Target Relationship, and Target Relatedness

\begin{tabular}{|c|c|c|c|c|c|c|c|c|c|c|c|c|}
\hline \multirow{4}{*}{$\begin{array}{c}\text { Prime } \\
\text { Cuing } \\
\text { Condition } \\
\end{array}$} & \multicolumn{12}{|c|}{ Target Relatedness } \\
\hline & \multicolumn{6}{|c|}{ Related } & \multicolumn{6}{|c|}{ Unrelated } \\
\hline & \multicolumn{2}{|c|}{ Identical } & \multicolumn{2}{|c|}{$\begin{array}{c}\text { Same } \\
\text { Category }\end{array}$} & \multicolumn{2}{|c|}{$\begin{array}{l}\text { Different } \\
\text { Category }\end{array}$} & \multicolumn{2}{|c|}{ Identical } & \multicolumn{2}{|c|}{$\begin{array}{c}\text { Same } \\
\text { Category }\end{array}$} & \multicolumn{2}{|c|}{$\begin{array}{l}\text { Different } \\
\text { Category }\end{array}$} \\
\hline & RT & $\mathrm{PE}$ & RT & $\mathrm{PE}$ & RT & $\mathrm{PE}$ & RT & $\mathrm{PE}$ & RT & $\mathrm{PE}$ & RT & $\mathrm{PE}$ \\
\hline \multicolumn{13}{|c|}{ Target on Top } \\
\hline Cued & 476 & .045 & 486 & .055 & 499 & .106 & 486 & .051 & 489 & .059 & 504 & .077 \\
\hline Uncued & 490 & .073 & 491 & .061 & 493 & .076 & 490 & .054 & 489 & .058 & 491 & .064 \\
\hline \multicolumn{13}{|c|}{ Target on Bottom } \\
\hline Cued & 479 & .042 & 487 & .055 & 501 & .073 & 494 & .036 & 502 & .041 & 515 & .071 \\
\hline Uncued & 494 & .055 & 490 & .045 & 496 & .060 & 501 & .045 & 508 & .046 & 504 & .042 \\
\hline
\end{tabular}


Identity repetition effects. As in the previous experiments, we examined the identity repetition effect including the data from the identical condition and different category condition. The overall identity repetition effect on RT was $12 \mathrm{msec}\left[F(1,76)=74.56, p<.0001, \eta_{\mathrm{p}}^{2}=\right.$ $.50]$; the RT was shorter when the prime and target were identical $(489 \mathrm{msec})$ than when they were from different categories $(501 \mathrm{msec})$. Most importantly, a substantial identity repetition effect was obtained when the prime was cued (with a $95 \%$ confidence interval of $21 \pm 4 \mathrm{msec}$ ) but not when it was uncued $(3 \pm 3 \mathrm{msec})[F(1,76)=66.69$, $\left.p<.0001, \eta_{\mathrm{p}}^{2}=.47\right]$; see Figure 4A. Simple main effects analyses confirmed that the identity repetition effect was significant for cued primes $[F(1,76)=99.26, p<.0001$, $\left.\eta_{\mathrm{p}}^{2}=.57\right]$. The effect was small for uncued primes and only approached significance $[F(1,76)=3.64, p=.0601$, $\left.\eta_{\mathrm{p}}^{2}=.05\right]$.
The PE data revealed an overall identity repetition effect of .021 $\left[F(1,76)=39.17, p<.0001, \eta_{\mathrm{p}}^{2}=.34\right]$; the $\mathrm{PE}$ was smaller when the prime and target were identical (.050) than when they were from different categories (.071). As in the RT data, the identity repetition effect on PE was obtained when the prime was cued $(.038 \pm .010$ at the $95 \%$ confidence interval) but not when it was uncued $(.004 \pm .008)\left[F(1,76)=33.33, p<.001, \eta_{\mathrm{p}}^{2}=.30\right] . \mathrm{Sim}-$ ple main effects analyses confirmed that the identity repetition effect was significant for cued primes $[F(1,76)=$ $\left.58.55, p<.0001, \eta_{\mathrm{p}}^{2}=.44\right]$, but not for uncued primes $(F<1)$.

Category congruency effects. The RT data analyses for the category congruency effect (including only the data from the same and different category conditions) showed that the overall category congruency effect on RT was $8 \mathrm{msec}\left[F(1,76)=44.95, p<.0001, \eta_{\mathrm{p}}^{2}=.37\right]$; the
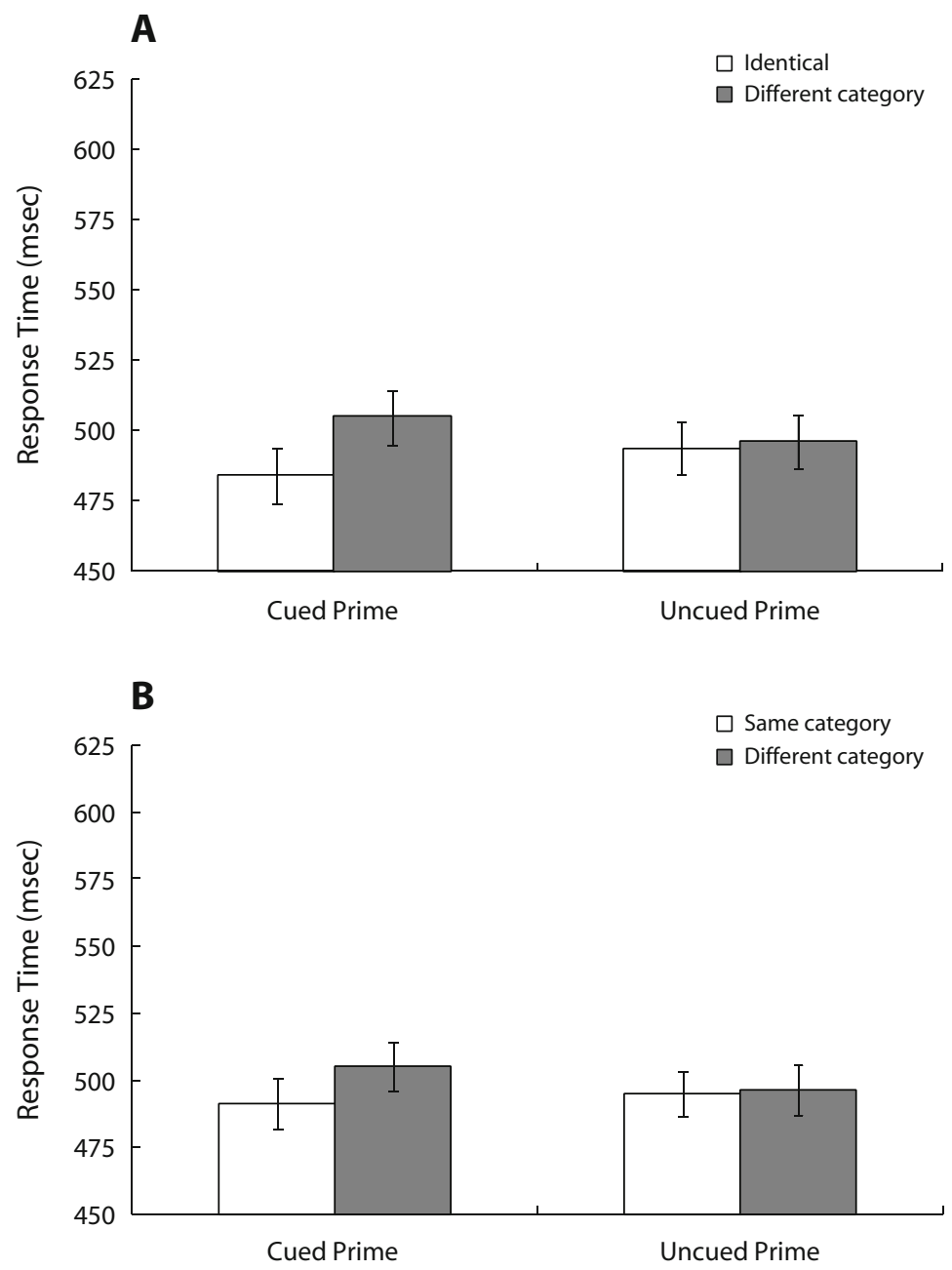

Figure 4. Mean response times (RTs) for cued and uncued primes in Experiment 3 as a function of prime-target relationship (identical, same category, or different category). (A) Mean RTs for the identical condition and the different category condition (the difference between these conditions is the identity repetition effect). (B) Mean RTs in the same category condition (excluding the identical trials) and the different category condition (the difference between these conditions is the category congruency effect). Error bars represent the standard errors of the means. 
RT was shorter when the prime and target were from the same category $(493 \mathrm{msec})$ than when they were from different categories $(501 \mathrm{msec})$. RT for the target word was $3 \mathrm{msec}$ shorter when the prime was uncued $(495 \mathrm{msec})$ than when it was cued $(498 \mathrm{msec})[F(1,76)=5.32, p<$ $\left..05, \eta_{\mathrm{p}}^{2}=.07\right]$, suggesting that the attended prime word slowed down the processing of the target word. Most importantly, the category congruency effect was obtained when the prime was cued (with a 95\% confidence interval of $14 \pm 3 \mathrm{msec})$ but not when it was uncued $(1 \pm 3 \mathrm{msec})$ $\left[F(1,76)=26.20, p<.0001, \eta_{\mathrm{p}}^{2}=.26\right]$; see Figure 4B. Simple main effects analyses confirmed that the category congruency effect was significant for cued primes $\left[F(1,76)=65.63, p<.0001, \eta_{\mathrm{p}}^{2}=.43\right]$ but not for uncued primes $(F<1)$.

The PE data analyses revealed similar patterns as in the RT data. The overall category congruency effect on PE was $.019\left[F(1,76)=32.28, p<.0001, \eta_{\mathrm{p}}^{2}=.04\right]$; the PE was smaller when the prime and target were from the same category (.052) than when they were from different categories (.071). PE for the target word was smaller when the prime was uncued $(.056)$ than when it was cued $(.067)\left[F(1,76)=14.64, p<.001, \eta_{\mathrm{p}}^{2}=.16\right]$. Most importantly, the category congruency effect obtained when the prime was cued (with a $95 \%$ confidence interval of $.029 \pm .009$ ) was much larger than that obtained when it was uncued $(.008 \pm .007)[F(1,76)=18.78, p<.0001$, $\left.\eta_{\mathrm{p}}^{2}=.20\right]$. Simple main effects analyses confirmed that the category congruency effect was significant for cued primes $\left[F(1,76)=42.98, p<.0001, \eta_{\mathrm{p}}^{2}=.36\right]$. Although the effect was significant for uncued primes $[F(1,76)=$ $\left.4.51, p<.05, \eta_{\mathrm{p}}^{2}=.06\right]$, it was quite small.

\section{Discussion}

Experiment 3 used only four words (two related and two unrelated from each category), which were repeated 160 times for each participant. Note that this frequency is similar to Stroop experiments, which typically repeat the same four color word stimuli (red, green, blue, and yellow). This change further reduced overall RT, from $546 \mathrm{msec}$ in Experiment 2 to only $494 \mathrm{msec}$.

Even when the words were repeated with such a high frequency (twice as often as in Experiment 2), the identity repetition effect and the category congruency effect were evident only when the prime was cued (attended), not when it was not (unattended). Replicating both Experiments 1 and 2, these findings suggest that spatial attention is needed for semantic activation even for familiar and expected words.

\section{GENERAL DISCUSSION}

In the present study, we examined whether semantic activation is possible for words presented outside of spatial attention. We proposed a variant of attention theory, in which such automatic semantic activation is possible for highly primed words, as would occur for recently presented words, or personally relevant words (e.g., one's own name). Automatic processing could occur because these words are held in short-term memory, or because recognition of these words requires less evidence to reach the threshold for identification (a sort of bias).

Such a mechanism favoring highly expected words is not only plausible but would also help to explain recent controversies in the literature. Previous work using a lexical decision paradigm, in which each word was presented only once, has suggested that semantic activation is not possible for unattended words (see, e.g., Chiappe et al., 1996; Dark et al., 1985; Lachter et al., 2004; Stolz \& McCann, 2000; Stolz \& Neely, 1995). Previous studies using the Stroop paradigm, however, have suggested that it is possible (e.g., Brown et al., 2002; Lachter et al., 2008; but see Besner et al., 1997, for a single colored-letter version of the Stroop paradigm). These Stroop studies typically involved only four or fewer color words, presented repeatedly throughout the experiment. The high frequency of presentation might have minimized the need for spatial attention in semantic activation.

To evaluate this attractive hypothesis, Experiment 1 used a large set of words (162), each repeated only four times for each participant, whereas Experiments 2 and 3 used a small set of words ( 8 vs. 4 , respectively) repeated 80 and 160 times, respectively. We used a categorization paradigm, in which participants indicated whether the target word belonged to a prespecified category. Our methodology emphasized the need to control the locus of spatial attention and prevent slippage to "unattended" prime words (e.g., Lachter et al., 2004). We presented the targets and primes in a fixed location for each participant, so there was no reason to endogenously attend the primes. In addition, the prime word was presented for only $50 \mathrm{msec}$, followed by a mask, so that it did not have time to capture attention prior to being extinguished. We also used a rapid sequence of 3 nonwords as a cue to capture spatial attention. In the unattended prime condition, we used these cues to further ensure the allocation of attention to the target location and not the prime location. In the attended prime condition, we used these cues to attract attention to the prime, to verify that, when attended, primes are sufficiently visible to produce substantial identity repetition and category congruency effects.

\section{Summary of Experimental Findings}

In Experiment 1, where each word was repeated only 4 times per participant, both the identity repetition effect and the category congruency effect were obtained only when the prime was cued (attended), not when it was uncued (unattended). Similar results were obtained even when the frequency of word repetitions dramatically increased in Experiments 2 (80 repetitions per session) and 3 (160 repetitions). An additional data analysis with experiment as a between-subjects variable showed that overall RT decreased sharply as the frequency of word repetitions increased $\left[F(2,207)=46.33, M S_{\mathrm{e}}=181,383\right.$, $p<.0001]$; mean RT was 597, 546, and $494 \mathrm{msec}$ for Experiments 1,2, and 3, respectively. This result confirms that manipulating the frequency of word repetitions did in fact have a substantial effect on performance.

For cued (i.e., attended) primes, the overall identity repetition effect, averaged across all three experiments, was 
$22 \pm 3 \mathrm{msec}$ ( $95 \%$ confidence interval), and the category congruency effect was $15 \pm 2 \mathrm{msec}$. For uncued (i.e., unattended) primes, however, both the identity repetition and category congruency effects were only $2 \pm 2 \mathrm{msec}$. We conducted between-experiments analyses on the identity repetition effect and the category congruency effect, including the variables of experiment and prime cuing condition. The interaction between these variables was not significant for the identity repetition effect $(F<1)$ or for the category congruency effect $[F(2,207)=2.43, p=.09$, $\left.\eta_{\mathrm{p}}^{2}=.26\right]$.

\section{Evidence for No Semantic Activation Without Spatial Attention}

Two main conclusions can be drawn from the present results. First, the absence of identity repetition and category congruency effects from unattended words in Experiment 1 shows that this phenomenon is not just a quirk of the lexical decision paradigm (Lachter et al., 2004) and further supports the conclusion that semantic activation of infrequently presented words requires spatial attention. This result held even though the categorization paradigm encourages participants to think about a particular category and generate expectancies for words within that category (i.e., spreading activation in semantic memory).

Second, and most importantly, these results argue against the hypothesis that semantic activation outside spatial attention is possible for words that are highly expected, due to being recently presented many times. This account was inspired by recent findings using the Stroop paradigm (Lachter et al., 2008) and by Treisman's (1960) attenuation model. According to that model, unattended stimuli are attenuated but not completely filtered out. Thus, it seemed highly plausible that frequently presented and expected words, but not infrequently presented and unexpected words, could break through the attentional filter and be identified. Nevertheless, the present data provided no evidence for such an account.

The present findings further suggest that enhanced expectation caused the use of a small stimulus set and is not responsible for the discrepancy in results between the Stroop and lexical decision paradigms. When the total number of words used in the experiment was reduced from 160 in Experiment 1 to only 4 in Experiment 3, there was still no evidence for semantic activation without spatial attention (i.e., both the identity repetition effect and the category congruency effects were absent in the uncued [unattended] location). The present findings are also consistent with the absence of semantic activation from words appearing in parafoveal regions (presumably to be unattended) even when they are contextually related to the current task (e.g., Altarriba, Kambe, Pollatsek, \& Rayner, 2001; Rayner, White, Kambe, Miller, \& Liversedge, 2003).

\section{What Is Special About the Stroop Paradigm?}

Interestingly, a recent Stroop-naming study by Lachter et al. (2008; see also Brown et al., 2002) provided evidence that word identification sometimes occurs outside the focus of spatial attention. Color words produced sig- nificant Stroop effects even when measures similar to those taken in the present study were used to assure they were unattended. In that study, a small set of color words was repeated numerous times throughout the experiment (four words repeated about 122 times per participant in Experiment 1). The frequency of word presentation was nearly identical to that in the present Experiment 3, in which four words were repeated 160 times per session. Why was semantic activation outside spatial attention apparently possible in Lachter et al.'s (2008) study but not in the present study, even though the prime words were frequently repeated and highly expected in both experiments?

One possibility is that domain of processing on the target determines the demand for spatial attention. For instance, in the Stroop color-naming paradigm of Lachter et al. (2008), the target was a color bar and the distractor was a color word. Perhaps the processing of the color bar requires little spatial attention, thus freeing spatial attention to move somewhere other than the target location (e.g., Andersen, Müller, \& Hillyard, 2009). In contrast, both the prime and target in our categorization paradigm were words. Perhaps reading words requires spatial attention, thus limiting the ability of spatial attention to wander to the location of the prime word. This hypothesis would also explain the lack of evidence for semantic activation without spatial attention in Lachter et al.'s (2004) study, which used a lexical decision paradigm (word vs. nonword targets). Being aware of this issue, Lachter et al. (2008) placed a colored border around the color bar. Their goal was to encourage a tight focus of spatial attention, though there was no way to assess whether this effort was successful.

Although our hypothesis that domain of processing on the target determines the demand for spatial attention seems similar to the domain-specific processing hypothesis (e.g., Allport, 1980; Chiappe et al., 1996; Finkbeiner $\&$ Forster, 2008), there is a subtle difference. According to domain-specific processing, processing the target at the word or letter level makes demands on specific resources, which are then not available to other stimuli. In the lexical decision paradigm, for example, word processing on the target might utilize the resources needed to process the word primes. In the Stroop paradigm (e.g., Brown et al., 2002; Lachter et al., 2008), however, processing the target at the color level might not draw on the same resources required for word recognition. This domain-specific processing can explain some of the findings, but seems to make an incorrect prediction for the present study. Because the target and the prime need the same word processing resources, there should be no identity repetition effect and category congruency effect for both cued and uncued primes, contrary to our findings.

The second possibility is that the absence of identity repetition effect and category congruency effect from unattended words in the present study is due not only to the absence of spatial attention but also to an inhibitory mechanism specific to words. In the priming paradigm (adopted in the present study and in Lachter et al., 2004), two words are presented (prime, then target). When the 
target task involves processing a target word, the attentional system might block nontarget words from gaining access to word recognition mechanisms. In the Stroop paradigm, however, the target task typically involves naming ink color, so there is little incentive to block nontarget words from accessing word recognition mechanisms. This inhibitory hypothesis implies that word processing is capacity-limited. Consistent with this assumption, when an irrelevant color-neutral word is presented simultaneously with the color word, the Stroop effect is greatly reduced (e.g., Brown, Roos-Gilbert, \& Carr, 1995; Kahneman \& Chajczyk, 1983; but see, e.g., Cho, Lien, \& Proctor, 2006; Roberts \& Besner, 2005, for boundary conditions). This Stroop dilution effect implies that words do compete for word processing resources.

A third, somewhat related, explanation for the discrepancy in the findings between the Stroop paradigm and the categorization paradigm concerns the response competition activated by the irrelevant stimuli. In the Stroop paradigm, the irrelevant stimuli were typically color words. Processing of individual letters at the phonetic level would be sufficient to activate compatible or incompatible responses for the target stimuli (e.g., phonetic activation of the letter R in the word RED would make it easier to say RED for the target color red and more difficult to say GREEN for the target color green). In the present categorization paradigm, however, the related prime words and responses for the target words do not share phonetics, only semantics. To address this possibility, Lachter et al. (2008) used color-associated words (e.g., LEMON for yellow, SKY for blue) as irrelevant stimuli in their Experiment 3, because such words do not necessarily share any phonetics with the target color names. These stimuli produced only a 4-msec Stroop-like effect (albeit statistically significant), not substantially greater than the effects of the unattended primes in the present study. The last two explanations discussed above are logically possible and consistent with the available data; therefore, further studies will be needed to distinguish between them.

\section{Evaluation of Attenuation Theories}

We hypothesized that highly expected words within a given context (e.g., due to frequent repetition) would allow for more automatic semantic activation in the absence of spatial attention. As noted above, this hypothesis is related to, but distinct from, Treisman's (1960) attenuation theory. The hypothesis seemed plausible a priori, and could also explain why people sometimes notice important words (e.g., their own names; the "cocktail party effect") or expected words in an unattended channel (e.g., Treisman, 1960). It also would help explain why there is more evidence of word processing without attention in Stroop studies (where the same four color words/concepts are highly active) than in lexical decision studies (where each word is typically presented only once). Nevertheless, the present results provide no evidence for the claim that repetition or expectancy enables automatic semantic activation.

It is still unclear why words that are familiar (such as one's own name) or expected within a particular context are often detected even when attention is allocated somewhere else. For example, Moray (1959) noted that when shadowing one channel (e.g., the left ear) people sometimes notice their own names in the other (supposedly unattended) channel. Also, Treisman (1960) found that people told to shadow one channel would occasionally switch to the other channel if the content switched ears. As discussed by Lachter et al. (2004), these examples might not reflect leakage through the attention filter (i.e., semantic processing without spatial attention), but rather slippage of the attentional filter (see also Conway, Cowan, $\&$ Bunting, 2001). That is, participants might occasionally attend the so-called "unattended" channel (slippage) and only at that point begin to process the content semantically. In Treisman, for example, participants followed the message to the irrelevant ear only $6 \%$ of the time. It is easy to imagine attentional slippage of this modest magnitude, perhaps induced by the lack of coherence of the text in the to-be-shadowed ear. In summary, perhaps even highly expected words cannot be processed without spatial attention, but are more likely to be remembered if they do receive some spatial attention.

\section{Relation to Previous Word Recognition Studies}

Our present findings rule out the hypothesis that word repetition enables automatic semantic activation. They also support the claim that spatial attention is critically important in word processing, especially for semantic activation (see also Stolz \& McCann, 2000). This claim merits further discussion in the context of word recognition in general. A common assumption regarding word recognition is that it contains multiple, distinct processes (e.g., feature and letter processing, lexical activation, orthographic lexicon, phonological activation, and semantic activation; see Coltheart, Rastle, Perry, Langdon, \& Ziegler, 2001). Although our study suggests the need of spatial attention for semantic activation (or some earlier process), our results do not imply that all phases of word processing require spatial attention.

Previous studies suggest that lexical activation also requires spatial attention. McCann, Folk, and Johnston (1992) employed a lexical decision task in a cuing paradigm to examine the dependency between lexical activation and spatial attention. The critical manipulation was word frequency (the occurrence in the English language), which has been assumed to primarily affect lexical activation. They found similar cuing effects (faster responses following valid cues than following invalid cues) for highfrequency target words and low-frequency target words. These results suggest that spatial attention and lexical activation operate independently, and that spatial attention must be directed to the target stimulus in order to enable lexical processing.

Note that McCann et al.'s (1992) finding that even highfrequency words could not be processed outside of spatial attention is consistent with the present findings. That is, the familiarity of the word - regardless of whether it is induced by overall frequency of use in the English language or by local frequency within a certain context — does not promote automatic word processing. 


\section{Summary}

The present study provides further evidence that word reading depends critically on spatial attention (e.g., Besner et al., 1997; Chiappe et al., 1996; Dark et al., 1985; Lachter et al., 2004; Stolz \& Besner, 1999; Stolz \& McCann, 2000; Stolz \& Neely, 1995). One notable finding is that unattended words were not processed sufficiently to prime the categorization response to the target, even when those words were in the target set (consisting of only four words in Experiment 3) and recently presented with a high frequency (160 repetitions in Experiment 3). Although it is highly plausible that word expectancy and word repetition would strongly reduce the need for spatial attention, clearly they did not. Further research is needed to determine why the Stroop paradigm sometimes produces evidence of word reading outside the focus of attention (e.g., Brown et al., 2002; Lachter et al., 2008) when other paradigms do not.

\section{AUTHOR NOTE}

We are grateful for the financial support of the Aviation Safety Program of the National Aeronautics and Space Administration. We thank Jennifer Burt, Ken Forster, Lynne Nygaard, and an anonymous reviewer for their comments on the earlier versions of the manuscript. Correspondence concerning this article should be sent to M.-C. Lien, Department of Psychology, Oregon State University, Corvallis, OR 97331-5303 (e-mail: mei.lien@oregonstate.edu).

\section{REFERENCES}

Allport, A. (1980). Attention and performance. In G. Claxton (Ed.), Cognitive psychology: New directions (pp. 112-153). London: Routledge \& Kegan Paul.

Altarriba, J., Kambe, G., Pollatsek, A., \& Rayner, K. (2001). Semantic codes are not used in integrating information across eye fixations in reading: Evidence from fluent Spanish-English bilinguals. Perception \& Psychophysics, 63, 875-890.

Andersen, S. K., Müller, M. M., \& Hillyard, S. A. (2009). Colorselective attention need not be mediated by spatial attention. Journal of Vision, 9(6, Art. 2), 1-7.

Ballard, D. H. (1991). Animate vision. Artificial Intelligence, 48, 5786.

Besner, D., Stolz, J. A., \& Boutilier, C. (1997). The Stroop effect and the myth of automaticity. Psychonomic Bulletin \& Review, 4, 221-225.

Brown, T. L., Gore, C. L., \& CARr, T. H. (2002). Visual attention and word recognition in Stroop color naming: Is word recognition "automatic"? Journal of Experimental Psychology: General, 131, 220-240.

Brown, T. L., Roos-Gilbert, L., \& CARr, T. H. (1995). Automaticity and word perception: Evidence from Stroop and Stroop dilution effects. Journal of Experimental Psychology: Learning, Memory, \& Cognition, 21, 1395-1411.

Chiappe, P. R., Smith, M. C., \& Besner, D. (1996). Semantic priming in visual word recognition: Activation blocking and domains of processing. Psychonomic Bulletin \& Review, 3, 249-253.

Cho, Y.-S., Lien, M.-C., \& Proctor, R. W. (2006). Stroop dilution depends on the nature of the color carrier but not on its location. Journal of Experimental Psychology: Human Perception \& Performance, 32, 826-839.

Coltheart, M., Rastle, K., Perry, C., Langdon, R., \& Ziegler, J. (2001). DRC: A dual route cascaded model of visual word recognition and reading aloud. Psychological Review, 108, 204-256.

Conway, A. R. A., Cowan, N., \& Bunting, M. F. (2001). The cocktail party phenomenon revisited: The importance of working memory capacity. Psychonomic Bulletin \& Review, 8, 331-335.

Dark, V. J., Johnston, W. A., Myles-Worsley, M., \& Farah, M. J. (1985). Levels of selection and capacity limits. Journal of Experimental Psychology: General, 114, 472-497.
FinKBEINER, M., \& Forster, K. I. (2008). Attention, intention, and domain-specific processing. Trends in Cognitive Sciences, 12, 59-64.

Folk, C. L., Remington, R. W., \& Johnston, J. C. (1992). Involuntary covert orienting is contingent on attentional control settings. Journal of Experimental Psychology: Human Perception \& Performance, 18, 1030-1044.

Forster, K. I., \& Davis, C. (1984). Repetition priming and frequency attenuation in lexical access. Journal of Experimental Psychology: Learning, Memory, \& Cognition, 10, 680-698.

Fuentes, L. J., Carmona, E., Agis, I. F., \& Catena, A. (1994). The role of the anterior attention system in semantic processing of both foveal and parafoveal words. Journal of Cognitive Neuroscience, 6, 17-25.

Fuentes, L. J., \& Tudela, P. (1992). Semantic processing of foveally and parafoveally presented words in a lexical decision task. Quarterly Journal of Experimental Psychology, 45A, 299-322.

Fuster, J. M. (1990). Inferotemporal units in selective visual attention and short-term memory. Journal of Neurophysiology, 64, 681-697.

Fuster, J. M., \& JeRVEY, J. P. (1981). Inferotemporal neurons distinguish and retain behaviorally relevant features of visual stimuli. Science, 212, 952-955.

Gatti, S. V., \& Egeth, H. E. (1978). Failure of spatial selectivity in vision. Bulletin of the Psychonomic Society, 11, 181-184.

Haenny, P. E., Maunsell, J. H., \& Schiller, P. H. (1988). State dependent activity in monkey visual cortex. II. Retinal and extraretinal factors in V4. Experimental Brain Research, 69, 245-259.

Heil, M., Rolke, N., \& Pecchinenda, A. (2004). Automatic semantic activation is no myth: Semantic context effects on the N400 in the letter-search task in the absence of response time effects. Psychological Science, 15, 852-857.

Kahneman, D., \& ChajczyK, D. (1983). Tests of the automaticity of reading: Dilution of Stroop effects by color-irrelevant stimuli. Journal of Experimental Psychology: Human Perception \& Performance, 9 , 497-509.

Kirsner, K., \& Speelman, P. (1996). Skill acquisition and repetition priming: One principle, many processes? Journal of Experimental Psychology: Learning, Memory, \& Cognition, 22, 563-575.

LaBerge, D., \& Samuels, S. J. (1974). Toward a theory of automatic information processing in reading. Cognitive Psychology, 6, 293-323.

LACHTER, J., Forster, K. I., \& RUthrufF, E. (2004). Forty-five years after Broadbent (1958): Still no identification without attention. Psychological Review, 111, 880-913.

Lachter, J., Ruthruff, E., Lien, M.-C., \& McCann, R. S. (2008). Is attention needed for word identification? Evidence from the Stroop paradigm. Psychonomic Bulletin \& Review, 15, 950-955.

Lien, M.-C., Ruthruff, E., Cornett, L., Goodin, Z., \& Allen, P. A. (2008). On the nonautomaticity of visual word processing: Electrophysiological evidence that word processing requires central attention. Journal of Experimental Psychology: Human Perception \& Performance, 34, 751-773.

MaCLEOD, C. M. (1991). Half a century of research on the Stroop effect: An integrative review. Psychological Bulletin, 109, 163-203.

Maunsell, J. H. R., Nealey, T. A., Sclar, G., \& DePriest, D. D. (1989). Representation of extraretinal information in monkey visual cortex. In D. Lam (Ed.), Proceedings of the Retinal Research Foundation Symposium (pp. 223-235). Woodlands, TX: Portfolio.

McCann, R. S., Folk, C. L., \& Johnston, J. C. (1992). The role of spatial attention in visual word processing. Journal of Experimental Psychology: Human Perception \& Performance, 18, 1015-1029.

Meyer, D. E., \& SchVANEveldt, R. W. (1971). Facilitation in recognizing pairs of words: Evidence of a dependence between retrieval operations. Journal of Experimental Psychology, 90, 227-234.

Miyashita, Y., \& Chang, H. S. (1988). Neuronal correlate of pictorial short-term memory in the primate temporal cortex. Nature, 331, 68-70.

Moray, N. (1959). Attention in dichotic listening: Affective cues and the influence of instructions. Quarterly Journal of Experimental Psychology, 11, 56-60.

NeELY, J. H. (1991). Semantic priming effects in visual word recognition: A selective review of current findings and theories. In D. Besner \& G. W. Humphreys (Eds.), Basic processes in reading: Visual word recognition (pp. 264-336). Hillsdale, NJ: Erlbaum.

NeELY, J. H., \& Kahan, T. A. (2001). Is semantic activation automatic? 
A critical re-evaluation. In H. L. Roediger III, J. S. Nairne, I. Neath, \& A. M. Surprenant (Eds.), The nature of remembering: Essays in honor of Robert G. Crowder (pp. 69-93). Washington, DC: APA.

Rayner, K., White, S. J., Kambe, G., Miller, B., \& Liversedge, S. P. (2003). On the processing of meaning from parafoveal vision during eye fixations in reading. In J. Hyönä, R. Radach, \& H. Deubel (Eds.), The mind's eye: Cognitive and applied aspects of eye movement research (pp. 213-234). Amsterdam: Elsevier.

Roberts, M. A., \& Besner, D. (2005). Stroop dilution revisited: Evidence for domain-specific, limited-capacity processing. Journal of Experimental Psychology: Human Perception \& Performance, 31, 3-13.

Rossi, A. F., \& Paradiso, M. A. (1995). Feature-specific effects of selective visual attention. Vision Research, 35, 621-634.

SiÉroff, E., \& Posner, M. I. (1988). Cueing spatial attention during processing of words and letter strings in normals. Cognitive Neuropsychology, 5, 451-472.

Stanovich, K. E., \& West, R. F. (1981). The effect of sentence context on ongoing word recognition: Tests of a two-process theory. Journal of Experimental Psychology: Human Perception \& Performance, 7, 658-672.

Stolz, J. A., \& Besner, D. (1999). On the myth of automatic semantic activation in reading. Current Directions in Psychological Science, 8, 61-65.

Stolz, J. A., \& McCann, R. S. (2000). Visual word recognition: Reat- tending to the role of spatial attention. Journal of Experimental Psychology: Human Perception \& Performance, 26, 1320-1331.

Stolz, J. A., \& Neely, J. H. (1995). When target degradation does and does not enhance semantic context effects in word recognition. Journal of Experimental Psychology: Learning, Memory, \& Cognition, 21, 596-611.

Stolz, J. A., \& Stevanovski, B. (2004). Interactive activation in visual word recognition: Constraints imposed by the joint effect of spatial attention and semantics. Journal of Experimental Psychology: Human Perception \& Performance, 30, 1064-1076.

Stroop, J. R. (1935). Studies of interference in serial verbal reactions. Journal of Experimental Psychology, 18, 643-662.

Treisman, A. M. (1960). Contextual cues in selective listening. Quarterly Journal of Experimental Psychology, 12, 242-248.

\section{NOTE}

1. Eighteen out of the 20 categories, excluding the categories "Color" and "Fish," from Lien et al.'s (2008) study were used in Experiment 1. There were 17 related words in each category in Lien et al.'s study, but we added one more related word per category (for a total of 18 related words) in the present study.

(Manuscript received August 15, 2009; revision accepted for publication January 23, 2010.) 